\title{
Credit Risk Management of Commercial Banks in China
}

\author{
Jin-Mian HAN ${ }^{\mathrm{a},{ }^{*}}$ and Bin JIA \\ School of Economics and Management, Northwest University, Xi'an 710127, China \\ ajinmianh@ nwu.edu.cn, b3412996755@qq.com \\ ${ }^{*}$ Corresponding author
}

\begin{abstract}
Keywords: Risk management, Credit risk, Commercial banks.
\end{abstract}
\begin{abstract}
Risk management is one of the core contents of commercial bank management. The capability of risk management represents the main competitiveness of commercial banks. Among all the risks that commercial banks face in China, credit risk is the most important one. In recent years, the non-performing assets of commercial banks in China have increased, and the situation of credit risk management has been paid great attention. This paper analyzes the current situation of credit risk of commercial banks in China and its causes. Then based on the KMV model, it measures the credit risk of a commercial bank. Finally, the countermeasures and suggestions on credit risk management of commercial banks in China are put forward.
\end{abstract}

\section{Introduction}

The credit risk is the risk of default on a debt that may arise from a borrower failing to make required payments.[1] In banking, credit risk is defined as the potential that a bank borrower or counterparty will fail to meet its obligations in accordance with agreed terms. Under the background of the downward pressure on macro economy, the continuous upgrading of industrial structure and the economic development entering the New Normal in China, the credit risk of commercial banks has increased. The non-performing loans and non-performing loan ratio of commercial banks has continued to increase by "double rising". The provision coverage level of commercial banks has continued to decline. With the gradual slowdown of China's economic growth, the credit risk in the industries such as manufacturing, wholesale and retail industries is on the rise. On the other hand, in recent years, the decrease of production capacity and leverage ratio has caused downward pressure on asset quality of commercial bank loans. Moreover, influenced by the liberation of interest rates, the net interest margin of commercial banks has narrowed year by year. The profitability of interbank business of medium and small-sized banks has decreased to a certain extent. The growth of asset impairment loss has continued to erode the net profit. Although commercial banks try to replenish their capital through various channels, due to the level of capital adequacy has declined, some banks are under some replenishment pressure of capital.

In the academic research on credit risk management of commercial banks, Bossone[2] argues that credit is the subjective judgment of the contractual party on whether the counterparty will fulfill the contract or not when facing uncertainty. Based on the theory of information economics, Leland and Pyle[3] proves that due to the difference of information in credit business, commercial banks will have adverse selection before lending. Ali Fatemi and Iraj Fooladi[4] points out that credit risk is the forefront of financial services companies' risk activities. In terms of credit risk measurement, Altman et al. [5] came up with the Z-score model. Since 1990, a number of new measurement models have emerged, mainly including the JP Morgan's Credit Metrics model, KMV model (Kealshofer et al. [6]), the Creditrisk ${ }^{+}$model of Credit Suisse and the Credit Portfoh View model of McKinsey (CPV). In domestic studies, Wang Chunfeng et al. [7] used neural network technology for credit risk assessment. Xu Jiana et al [8] combined AHP with artificial neural network credit risk assessment techniques to establish an AHP-ANN model of credit risk assessment. Yuan Li-Li [9] analyzed the credit risk management of China's small and medium-sized commercial banks based on Chongqing Bank. In conclusion, the existing research on the credit risk of commercial banks provides a good foundation for this research. After entering the New Normal in China, credit risk of 
commercial banks has been increasing and showing new characteristics. In view of this, this paper analyzes the current situation of credit risk of commercial banks in China and its causes, measures the risks and puts forward suggestions for the credit risk management of commercial banks in China.

\section{The Current Situation of Credit Risk of Commercial Banks and Its Causes in China}

\section{The Current Situation of Credit Risk of Commercial Banks in China}

The credit risk of commercial banks is mainly reflected in the non-performing loans. From 2011 to 2016, the non-performing loan balances and ratios of commercial banks in China all increased. At the end of June 2017, the non-performing loan balance of commercial banks in China was $1,635.8$ billion RMB, up $13.81 \%$ over the same period of 2016. The non-performing loans of commercial banks have not yet bottomed out, and asset quality is still under downward pressure. Credit risk has been concentrated. In the distribution of credit risk, large commercial banks account for the majority. Rural commercial banks have the highest non-performing loan ratio, the credit risk management ability of which may be in insufficient.

\section{The Causes of Credit Risk of Commercial Banks in China}

Internal Factors. (1) Inadequate loan management capability. The most important business of commercial banks is the credit business. In the pre-credit business of the bank, it is necessary to fully understand the customer's credit rating and the financial status of the customer. After doing the business with customers, they also need to track and supervise their clients. If their supervision is not in place, they will easily cause customers to default or the loans will be overdue, which will have an impact on the bank's business development.

(2) Lack of good risk management team. A good management team is a key element of credit risk control. Credit risk has always existed and is inevitable. Therefore, it is necessary to have an experienced risk management team to operate and formulate corresponding strategies and methods to deal with the risks flexibly and effectively. The management team needs to identify the risks and measure and manage the risks.

(3) Low risk awareness. Chinese commercial banks once have focused on marketing and tried to occupy more market share. Bank employees have not form a strong sense of risk awareness. They consider measuring and handling the credit risk the responsibility of the risk management department, leading to the risk that could be dealt with fails to get timely control, and causing great losses to the bank.

External Factors. (1) Macroeconomic downward pressure. On December 26, 2017, WIND China Macroeconomic Forecast (CMF) disclosed a total of 23 financial institutions on the 2018 growth rate forecast. They believe that economic growth in 2018 will slightly decline from 2017. As the domestic macroeconomic downturn, the credit risk of banking industry's has been exposed continuously. There has been more pressure on the deterioration of a number of asset quality indicators such as non-performing assets. The problems of corporate debt escaping in some areas are exacerbated and the credit environment in the region is deteriorating.

(2) Government intervention. The president of China's national commercial banks is generally elected directly by the state instead of through the board of directors. Therefore, the decision of the president has a certain will of the government. At the same time, China's commercial banks are closely related to the government departments. Commercial banks usually give loans for government cooperative projects and projects supported by them. However, the repayment ability of these projects is not necessarily optimistic, laying a hidden credit risk.

(3) Bad social credit environment. The social credit environment in China needs improving. Common misdeeds such as capital fraud, tax fraud, and breach of contract, delinquent accounts, fake advertisements, and fictitious messages on the internet are common occurrences in capital markets, commercial transactions and personal consumption. The lack of credit has become the "bottleneck" of the current economic and social development. It leads to credit risks of China's 
market economy.

\section{The Measurement of Credit Risk of a Commercial Bank Based on KMV Model \\ Data Source}

This paper uses KMV model to measure the credit risk of $\mathrm{X}$ branch of $\mathrm{G}$ bank. It randomly selects 9 listed companies in credit business of this branch. The sample is from January 1, 2016 to December 31, 2016, the financial indicators of all enterprises are subject to the annual financial report.

\section{Credit Risk Measurement}

(1) Assuming the debt maturity period t and the risk-free interest rate $r$, in order to facilitate the data processing, the paper takes $\mathrm{t}=1$ and the $\mathrm{r}=2.5 \%$, which is the benchmark deposit interest rate announced in 2016 .

(2) Default point DPT calculation. The default point is a function of long-term liabilities and current liabilities. The critical point where the default occurs most frequently is that the assets of the company are greater than or equal to the current liabilities plus $50 \%$ of the long-term liabilities, namely: DPT = STD + $0.5 *$ LTD, where, STD is current liabilities and LTD is long-term liabilities

(3) Assumptions and calculation of the market value of firm equity $E\left(V_{E}\right)$. In this study, assuming that the expected growth rate of the firm's asset value is zero, the equity market value $\mathrm{E}$ $\left(\mathrm{V}_{\mathrm{E}}\right)=$ Total Share Capital * Closing Price of the Base Date

(4) Calculation of the volatility of the stock value. In this paper, the Moving Average Method is used to calculate the volatility of the stock value. $\sigma=\sqrt{\frac{1}{n-1} \sum_{i=1}^{n}\left(u_{i}-\bar{u}\right)^{2}}$

The calculation results are as follows:

Table 3-1 The calculation results of $D P T, \mathrm{v}_{E}, \sigma_{E}$

\begin{tabular}{lccc}
\hline Stock name & $D P T$ & \multicolumn{1}{l}{$V_{E}$} & $\underline{\sigma_{E}}$ \\
\hline Datang Generation & 1140.36 & 508.442 & 0.194040767 \\
CCOOP & 169.35 & 509.4784 & 0.40816204 \\
State Power & 1432.94 & 601.29 & 0.21906861 \\
Broadcast Network & 30.865 & 78.771 & 0.475817034 \\
Shaanxi Coal & 429.57 & 485 & 0.432907962 \\
Xi'an Tourism & 5.7863 & 35.2419 & 0.503770598 \\
Aviation Power & 299.37 & 635.374 & 0.282228108 \\
China Construction Bank & 119250 & 12900.5676 & 0.201381938 \\
China Railway Group & 5516.4 & 2023.9784 & 0.374337116 \\
\hline
\end{tabular}

(5) Calculation of enterprise assets value and its volatility

According to the KMV model, the formula for calculating the asset value of an enterprise and its volatility is as follows: 
$V_{A}=\frac{V_{E}+D P T \mathrm{e}^{-r T} N\left(d_{2}\right)}{N\left(d_{1}\right)}, \sigma_{A}=\frac{V_{E}}{V_{A} N\left(\mathrm{~d}_{1}\right)} \sigma_{E}$

Matlab7.0 software is used for the calculation. The results are as follows:

Table 3-2 The calculation results of $V_{A}, \sigma_{A}$

\begin{tabular}{lcc}
\hline Stock name & \multicolumn{1}{l}{$V_{A}$} & \multicolumn{2}{l}{$\sigma_{A}$} \\
\cline { 2 - 3 } Datang Generation & 1620.6 & 0.0609 \\
CCOOP & 674.6471 & 0.3082 \\
State Power & 1998.9 & 0.0659 \\
Broadcast Network & 108.8735 & 0.3443 \\
Shaanxi Coal & 903.9464 & 0.2323 \\
Xi'an Tourism & 40.8853 & 0.4342 \\
Aviation Power & 927.3525 & 0.1934 \\
\multicolumn{1}{c}{ China Construction Bank } & 129210 & 0.0201 \\
China Railway Group & 7404 & 0.1024
\end{tabular}

(6) The default distance DD and the expected default rate EDF determination

Default distance DD and expected default rate EDF are calculated as follows: $D D=\frac{V_{A}-D P T}{\sigma_{A} V_{A}}, E D F=1-N(D D)$

Table 3-3 The calculation results of DD and EDF

\begin{tabular}{lcc}
\hline Stock name(abrev.) & DD & EDF \\
\hline Datang Generation & 4.868172 & $0.000056 \%$ \\
CCOOP & 2.429897 & $0.955155 \%$ \\
State Power & 4.296192 & $0.000869 \%$ \\
Broadcast Network & 2.081207 & $0.870747 \%$ \\
Shaanxi Coal & 2.25867 & $1.195197 \%$ \\
Xi'an Tourism & 1.976982 & $2.402184 \%$ \\
Aviation Power & 3.502014 & $0.023088 \%$ \\
China Construction Bank & 3.832371 & $0.006346 \%$ \\
China Railway Group & 2.489504 & $0.6396076 \%$
\end{tabular}




\section{Recommendations for the Credit Risk Management of the Commercial Banks in China}

After analyzing and measuring the credit risks of commercial banks in China, this paper put forward the following recommendations for the credit risk management.

First, strengthen the credit risk identification. Most of the non-performing loans are hidden from the beginning of the pre-loan investigation. The credit business manager must track the enterprise's operation and financial condition, and control the credit risk from the source. Second, pay attention to credit risk assessment. So far, there are models such as KMV, CPV and logistic for credit risk assessment, but there are few models developed by commercial banks in China. The bank should establish a credit risk model that suits the domestic economic environment, so the risk can be better produced, identified, and dealt with. Third, focus on post-loan credit risk management. The risk manager can go to the enterprise more and to know more about the production and operation of the enterprise and check the status of inventory and collateral in time. Fourth, intensify the disposal of non-performing loans. The loans should be reported immediately after the bad loans have been formed. The bank can speed up the progress of judicial cooperation in handling non-performing assets and strive for early results. External clearance and other means can also been used to fully tap the potential of non-performing loans.

\section{References}

[1] BIS. Principles for the Management of Credit Risk - final document. Basel Committee on Banking Supervision. September 2000.

[2] Biagio Bossone .Circuit Theory of Banking and Finance [J]. Journal of Banking \& Finance, 2001, 25 (05): 857-890.

[3] Lenand, Hand D.Pyle. Informational asymmetries, financial structure and financial intermediation[J].Journal of Finance, 1977,32(02):371-387.

[4] Ali Fatemi, IrajFooladi,"Credit risk management: a survey of practices", Managerial Finance, 2006(32): 227-233

[5] Altman E. I., Haldeman R. G., Narayanan P. Zeta Analysis: A New Model to Identify Bankruptcy Risk of Corporations [J]. Journalof Banking and Finance, 1977,1 (1 ):29-54. [16]

[6] Kealhofer Stephen and Matthew Kurbat, The default prediction power of the Merton approach, Relative to debt ratings and accounting variables, KMV LLC, 2001.

[7] Wang Chunfeng, Wan Haihui, Zhang Wei. Corporate Bank Credit Risk Assessment and Empirical Research [J].Journal of Management Sciences, 1998(01).

[8] Xu Jiana, Xi Bao: Credit Risk Assessment of Commercial Bank Based on AHP-ANN Model [J]: Journal of Harbin University of Technology. 2004(3):12-15

[9] Yuan Lili. Credit Risk Management of China's Commercial Banks: Based on Bank of Chongqing[D]. Chongqing: Southwest University of Finance and Economics, 2013. 